\title{
Stimulated Hyposalivary Flow Rates in Healthcare Students in an Interprofessional Awareness Educational Program Curriculum
}

\author{
R. Constance Wiener, ${ }^{1}$ Susan Morgan, ${ }^{2}$ Lauren Swager, ${ }^{3}$ \\ Christina DeBiase, ${ }^{4}$ and Christa L. Lilly ${ }^{5}$ \\ ${ }^{1}$ Dental Practice and Rural Health, West Virginia University, Health Sciences Addition, Room 104a, P.O. Box 9448, \\ Morgantown, WV 26506, USA \\ ${ }^{2}$ Department of Periodontics, West Virginia University, Rm 1087 HSN, P.O. Box 9490, Morgantown, WV 26506, USA \\ ${ }^{3}$ Behavioral Medicine and Psychiatry, West Virginia University, 930 Chestnut Ridge Road, P.O. Box 9137, \\ Morgantown, WV 26506, USA \\ ${ }^{4}$ School of Dentistry Academic Affairs, One Medical Center Drive, Rm 1038 HSC North, P.O. Box 9402, \\ Morgantown, WV 26506-9402, USA \\ ${ }^{5}$ Department of Biostatistics, West Virginia University, G103F HSC North, P.O. Box 9190, Morgantown, WV 26506, USA
}

Correspondence should be addressed to R. Constance Wiener; rwiener2@hsc.wvu.edu

Received 4 April 2017; Revised 14 June 2017; Accepted 19 June 2017; Published 18 July 2017

Academic Editor: Friedrich Paul Paulsen

Copyright (C) 2017 R. Constance Wiener et al. This is an open access article distributed under the Creative Commons Attribution License, which permits unrestricted use, distribution, and reproduction in any medium, provided the original work is properly cited.

\begin{abstract}
Purpose. Hyposalivation influences quality of life and medication compliance. However, oral health knowledge (in general) and knowledge about hyposalivation (in particular) are often lacking in nondental healthcare professional's curricula. Additionally, hyposalivation has not been adequately studied in young adults. The purpose for this study is twofold: to use an interprofessional educational curriculum to increase nondental healthcare students' knowledge about oral health and salivary testing and determine whether hyposalivation is different between sexes in young adults. Method. First-year medical and pharmacy students $(N=178)$ learned the process of saliva collection and provided samples in an interprofessional program. Results. There were $14.4 \%$ of participants with hyposalivation; $72.0 \%$ were female. Males had higher flow rates $(P=0.005)$. There failed to be a significant difference between the sexes with frank hyposalivation. There failed to be a significant difference in hyposalivation and medication use/nonuse. Conclusions. Hyposalivation is a biomedical, public health concern. However, in this young population, there was no significant difference between sexes or in medication use/nonuse. Through participation in the program, the students learned about salivary flow rates and the need for collaboration among professionals to prevent negative impacts of hyposalivation and oral health.
\end{abstract}

\section{Introduction}

Previous researchers have indicated that although there is increasing evidence of the association of oral health and general health, oral health education in undergraduate and graduate medical education is lacking $[1,2]$. The lack of knowledge was formally documented to be the result of the limited extent to which oral health content is presented in nondental professional programs [2]. In that study, the inclusion of oral-systemic science was rated as only somewhat important by $53.7 \%$ of responding administrators of nursing, pharmacy, and medical schools. Although dental education at one time focused on mechanical techniques and detail, the curriculum has broadened to include sophisticated biomedical concepts, psychosocial concepts, public health epidemiology, oral-systemic science, pain, craniofacial defects, trauma, cancer, and tobacco cessation (among other topics) in a multicultural environment [3]. The broader curriculum has increased referrals from dentistry to other health professions.

However, the old paradigm of a dentist as only a tooth doctor [2] and the historic separation of medical and dental education and patient care [4] have influenced the attitude 
that oral-systemic science is only somewhat important to medicine, nursing, and pharmacy. There is an urgent need for collaboration, prevention, patient counseling, and dental referrals by nondental healthcare providers [4]. Physicians are more likely to see poor children early than dentists are, and physicians are encouraged to provide dental anticipatory guidance. There is a significant need to bridge the lack of knowledge and increase the attitude of oral health importance given the consequences of neglected oral disease and the suffering associated with it [4]. Programs such as the Smiles for Life Oral Health Curriculum [5] and the West Virginia University My First Patient Program were developed to meet those needs. In particular, one of the oral health components in the My First Patient Program was to increase the knowledge about saliva and hyposalivation and to determine the rates of salivary flow and saliva testing in a collaborative interprofessional learning setting.

Saliva is exceedingly important for oral and systemic health. In its buffering capacity, it protects the teeth from caries and the oral mucosa from erosions and mucositis. It facilitates the formation of a bolus of food, swallowing, and speaking. Prolonged hyposalivation increases the number of cariogenic, organisms (such as Streptococcus and Lactobacil$l u s$ ), and caries progression [6]. It can lead to tooth sensitivity and difficulty in defending against Candida albicans [7].

Hyposalivation can initiate a cascade of events. Hyposalivation limits bacterial clearance from the mouth, increasing the likelihood of periodontal disease. Periodontal disease is associated with systemic diseases (diabetes, chronic kidney disease [8], heart disease, etc.). Not only does oral disease influence systemic disease, but some systemic diseases and conditions influence saliva production. These include autoimmune disorders (such as Sjogren's syndrome, autoimmune liver diseases); endocrine diseases (such as diabetes, hypothyroidism), neurological disorders (such as CNS trauma, cerebral palsy); infectious diseases (such as HIV/ AIDS, hepatitis C); genetic disorders (such as cystic fibrosis, Prader-Willi syndrome); metabolic disturbances (such as malnutrition, eating disorders); cancer associated disturbances (head and neck radiotherapy, chemotherapy, etc.); among others [9].

Medications with antisialogogue effects are the most frequent causes of hyposalivation [10]. Hyposalivation increases with polypharmacy and is especially likely with the daily use of more than 3 medications [11]. A dry mouth is not a trivial concern [12]. Some patients who have medication-induced low saliva flow may have dryness which is such a challenge that their drug regimen may need to be changed [13].

Patients often underreport inadequate saliva. People are not generally aware of having a dry mouth (even a transitory dry mouth) until there is an approximate $50 \%$ reduction in saliva $[14,15]$. Healthcare providers often overlook inadequate saliva as a condition/side-effect of medications [9]. However, educators developing the curriculum for interprofessional education programs are addressing the need to include information about hyposalivation early in the education of healthcare providers.

In the curriculum developed with the My First Patient Program, healthcare students are introduced to the confusing terminology related to oral dryness. For example, the term xerostomia refers to perceived oral dryness; the determination of the condition of xerostomia is made by the patient [16]. Hyposalivation is defined based upon measured stimulated flow rates (generally recognized as less than $1 \mathrm{ml} /$ minute [16]) or unstimulated flow rates. Researchers do not all agree as to the cut points to define hyposalivation $[17,18]$. Additionally, the term "dry mouth" has been defined and used inconsistently. It has been used to refer to perception, a visual observation, or measured salivary flow.

Much of the research relates to the perception of a dry mouth in older adults, with data collected by surveys. However, in two recent surveys of young adults, researchers found no apparent sex difference in the number of respondents reporting always having a dry mouth $[19,20]$. In another study of young adults, researchers did indicate a difference between the sexes for xerostomia (19.6\% in females and $14.6 \%$ in males) [21]. Researchers exploring xerostomia in different psychological disorders found more female patients than male patients had xerostomia [22]. They also found nearly half of patients with anxiety and depression, and over a third of patients with schizophrenia had xerostomia [22].

When saliva collection, rather than self-report, was used in studies, results were mixed. Researchers found that young adults did not have significant differences in some studies [23, 24]. However, in one study, researchers reported females had lower flow rates attributed (primarily) due to smaller salivary gland sizes associated with differences in body sizes [25].

The purpose of this study was to introduce salivary collection into an interprofessional curriculum and to determine whether hyposalivation (determined by stimulated salivary flow rate) differed between female and male healthcare students. The rationale was that it is important to determine factors associated with quality of life, oral health, and systemic health outcomes in determining salivary flow and that it is imperative for nondental professional students to understand the importance of oral health as a component in healthcare education.

Having knowledge about the oral health of young adults, particularly the prevalence of hyposalivation, will inform curricula specialists in health profession programs about important content that should be included in the curriculum.

\section{Material and Methods}

This study used the Krieger Ecological Theoretical Framework in which an outcome is the result of structural (demographic, community, politics) and biopsychosocial factors. A subset of data (2016 data) was used from the WVU My First Patient Program, 2013-2016, an interprofessional curriculum program in learning about one's own health. The premise of the My First Patient Program is that, by learning to care for oneself, one becomes a more effective healthcare provider. Participants for this study of hyposalivation included medical and pharmacy students who underwent a dental screening in $2016, N=178$. The screenings serve as the introduction to the oral health thread in the predoctoral medical and pharmacy curriculum. The mean age of the students was 22.6 years $($ median $=22$, mode $=22$, range $=20$, and SD $=2.63$ ). 
Decongestants

Antidepressants

Antihistamines

Appetite suppressants

Muscle relaxants

Diuretics

Anticholinergics

Antihypertensive

Antianxiety

Bronchodilators

Sedatives

Analgesics

Antipsychotic

Box 1: Medication list presented to the WVU My First Patient, 2016 participants.

West Virginia University (WVU) Institutional Review Board approval is on file and all studies were conducted in accordance with the Declaration of Helsinki (1964). The examiners for the program were dental students and dental faculty. Participants were not instructed to alter their daily routine for the screening; they were not instructed to avoid eating, drinking, chewing gum, brushing, or flossing. The menstrual cycle phase was not collected as a recent study indicated no significant effects of the menstrual cycle phase on unstimulated whole saliva flow [25]. Saliva sample collection occurred over the course of several workdays in August, 2016, from 11:00 a.m. to 6:00 p.m.

2.1. Key Dependent Variable. The primary outcome was stimulated salivary flow rate. Participants were instructed to chew a provided piece of wax (from the Saliva-Check Buffer ${ }^{\circledR}$ kit, GC America), for 5 minutes, and then to expectorate into preweighed tubes for 5 minutes. The tare weight of the tube was calculated and the stimulated salivary flow rate was determined using a saliva density of $1.0 \mathrm{~g} / \mathrm{ml}$ [24]. The variable for salivary flow rate was analyzed as both a continuous variable and a categorical (yes/no) variable based on the $1 \mathrm{ml} / \mathrm{minute}$ cut point for hyposalivation.

2.2. Key Independent Variables. There were two key independent variables, sex (male, female) and medication use (yes, no). The participants were given a list of 13 medication classes with known hyposalivation effects (Box 1). The participants were asked if they used any of the medications on the list and to provide the number of medications that they used. They were not asked to specify which medication from the list they were taking.

2.3. Other Variables. Other variables considered in the research were based upon the Krieger Ecological Theoretical Framework in which an outcome is the result of structural (demographic, community, politics), and biopsychosocial factors. These variables included race (recoded into nonHispanic white and other), community water fluoridation where he/she lives/works/goes to school (yes, no, and do not know), and participant's perception of having a dry mouth (yes/no).

2.4. Analysis. All analyses for this project were conducted with SAS 9.4. Statistical tests included descriptive statistics (frequency and valid percent for categorical variables and measures of central tendency and spread for continuous ones), bivariate analyses (Fisher's exact test for categorical variables or independent $t$-test for continuous variables), and logistic regression analyses. We conducted a series of logistic regression analyses on the presence of hyposalivation, to assess the adjusted odds ratios. We analyzed interaction terms; however, cell sizes were too small for model inclusion. Also, due to small cell sizes, multiple logistic regression models failed to converge. Further analyses were explored on the salivary flow using general linear model, with adjusted (least square) means pairwise comparisons included, as appropriate. Model assumptions for both the logistic regressions and general linear model were tested. The alpha for significance was determined a priori to be 0.05 .

\section{Results}

The sample included 178 participants, 67 (37.6\%) of whom were males. Of the 167 participants reporting race, $146(87.4 \%)$ were non-Hispanic white. There were 25 (14.37\%) participants who had hyposalivation; $72.0 \%$ were female, and all were non-Hispanic white. Twenty-three (12.9\%) participants reported using a medicine associated with hyposalivation. There were fewer than 10 participants reporting xerostomia. Details of the analyses are presented in Table 1.

The overall mean stimulated salivary flow rate for all participants was $1.53 \mathrm{ml} / \mathrm{minute}(\mathrm{SD}=0.73)$. When considering salivary flow as a continuous variable, there was a significant relationship ( $t=2.87 ; P=0.005)$ with males having a greater flow rate than females. The mean salivary flow rate for males was $1.73 \mathrm{ml} /$ minute; $\mathrm{SD}=0.78$ for males. The mean salivary flow rate for females was $1.41 \mathrm{ml} / \mathrm{minute}$ SD $=0.67$ for females.

The relationships of salivary flow rate with participant medication use failed to reach significance $(t=-.90 ; P=$ $0.37)$. The mean salivary flow rate for participants who did not use medications was $1.51 \mathrm{ml} /$ minute; $\mathrm{SD}=0.71$. The mean salivary flow rate for participants who did use medications was $1.66 \mathrm{ml} /$ minute; $\mathrm{SD}=0.84$ (Table 2 ).

The results of the logistic regression on hyposalivation as a categorical variable are presented in Table 3. In unadjusted logistic regression analysis, sex failed to reach a significant relationship with hyposalivation (odds ratio $=1.75,95 \%$ confidence interval: $0.69,4.49 ; P=0.24$ ). In unadjusted logistic regression, medication use failed to reach a significant relationship with hyposalivation (odds ratio $=1.30,95 \%$ confidence interval: $0.40,4.21 ; P=0.66$ ).

In a general linear model on salivary flow rate as a continuous variable with all two-way interactions included, the model including main effects was significant $(R$-square $=$ $0.10)$. Sex was a significant predictor of an increased salivary flow rate (Table 4). Specifically, males had higher salivary flow 
TABLE 1: Sample characteristics of WVU My First Patient, 2016. N (valid \%) reported.

\begin{tabular}{|c|c|c|c|c|c|c|c|}
\hline \multirow{2}{*}{ Variable } & \multirow{2}{*}{ Total } & \multicolumn{3}{|c|}{ Sex } & \multicolumn{3}{|c|}{ Hyposalivation } \\
\hline & & Females & Males & $P$ value & No & Yes & $P$ value \\
\hline Sex & 178 & - & - & - & - & - & - \\
\hline Male & $67(37.6 \%)$ & & & & & & \\
\hline Female & $111(62.4 \%)$ & & & & & & \\
\hline Hyposalivation & 174 & 106 & 67 & & - & - & - \\
\hline No & $149(85.6 \%)$ & $88(83.0 \%)$ & $60(89.6 \%)$ & 0.27 & & & \\
\hline Yes (<1 mg salivary flow) & $25(14.4 \%)$ & $18(17.0 \%)$ & $7(10.5 \%)$ & & & & \\
\hline Race & 167 & 102 & 64 & & 143 & 21 & \\
\hline Other & $21(12.6 \%)$ & $12(11.8 \%)$ & $9(14.1 \%)$ & 0.81 & $20(14.0 \%)$ & $0(0 \%)$ & 0.08 \\
\hline Non-Hispanic White & $146(87.4 \%)$ & $90(88.2 \%)$ & $55(85.9 \%)$ & 0.81 & $123(86.0 \%)$ & $21(100 \%)$ & 0.00 \\
\hline CWF & 169 & 105 & $63^{*}$ & & 140 & $25^{*}$ & \\
\hline No & $15(8.9 \%)$ & $12(11.4 \%)$ & & 0.17 & $13(9.3 \%)$ & & 1.00 \\
\hline Yes & $154(91.1 \%)$ & $93(88.6 \%)$ & & & $127(90.7 \%)$ & & \\
\hline Medication & 178 & 110 & 67 & & 149 & $25^{*}$ & \\
\hline No & $155(87.1 \%)$ & $99(90.0 \%)$ & $56(83.6 \%)$ & 024 & $130(87.3 \%)$ & & 075 \\
\hline Yes & $23(12.9 \%)$ & $11(10.0 \%)$ & $11(16.4 \%)$ & & $19(12.8 \%)$ & & \\
\hline Self-report dry mouth & $177^{*}$ & $110^{*}$ & $66^{*}$ & & $148^{*}$ & $25^{*}$ & \\
\hline $\begin{array}{l}\text { No } \\
\text { Yes }\end{array}$ & & & & 0.019 & & & 0.15 \\
\hline
\end{tabular}

$\mathrm{CWF}=$ community water fluoridation. ${ }^{*}$ Cell criteria are not reported as one or several of the criteria have small cell size(s) which could lead to participant identity.

TABLE 2: Sample characteristics and independent sample $t$-tests for salivary flow. WVU My First Patient, 2016.

\begin{tabular}{|c|c|c|c|c|c|}
\hline Variable & Number & Mean salivary flow & Standard deviation & $t$-value & $P$ value \\
\hline Overall salivary flow & 176 & 1.53 & 0.73 & - & - \\
\hline \multicolumn{6}{|l|}{ Hyposalivation } \\
\hline No & 148 & 1.67 & 0.68 & \multirow{2}{*}{ - } & \multirow{2}{*}{-} \\
\hline Yes (<1 mg salivary flow) & 25 & 0.76 & 0.51 & & \\
\hline \multicolumn{6}{|l|}{ Sex } \\
\hline Male & 66 & 1.73 & 0.78 & \multirow{2}{*}{2.87} & \multirow{2}{*}{0.005} \\
\hline Female & 109 & 1.41 & 0.67 & & \\
\hline \multicolumn{6}{|l|}{ Race } \\
\hline Other & 21 & 1.48 & 0.62 & \multirow{2}{*}{-0.39} & \multirow{2}{*}{0.70} \\
\hline Non-Hispanic White & 144 & 1.55 & 0.74 & & \\
\hline \multicolumn{6}{|c|}{ Community water fluoridation } \\
\hline No & 15 & 1.63 & 0.95 & \multirow{2}{*}{0.60} & \multirow{2}{*}{0.55} \\
\hline Yes & 152 & 1.51 & 0.71 & & \\
\hline \multicolumn{6}{|l|}{ Medication } \\
\hline No & 153 & 1.51 & 0.71 & \multirow{2}{*}{-0.90} & \multirow{2}{*}{0.37} \\
\hline Yes & 23 & 1.66 & 0.84 & & \\
\hline
\end{tabular}

TABle 3: Logistic regression results on hyposalivation. WVU My First Patient, 2016.

\begin{tabular}{|c|c|c|c|c|c|c|}
\hline Model & Predictors & Estimate (se) & $P$ value & Odds ratio & 95\% CI lower & 95\% CI upper \\
\hline \multirow{3}{*}{ Model 1: unadjusted sex } & Sex & & & & \multirow{4}{*}{0.69} & \multirow{4}{*}{4.46} \\
\hline & Female & $0.28(0.24)$ & 024 & 1.75 & & \\
\hline & Male & Reference & 0.27 & Reference & & \\
\hline \multirow{3}{*}{ Model 2: unadjusted medication } & Medication & & & & & \\
\hline & Yes & $0.13(0.30)$ & 0.66 & 1.30 & \multirow{2}{*}{0.40} & \multirow{2}{*}{4.21} \\
\hline & No & Reference & & Reference & & \\
\hline
\end{tabular}

$\mathrm{CI}=$ confidence interval. 
TABLE 4: General linear model results on overall salivary flow, all two-way interactions included.

\begin{tabular}{lcccc}
\hline Source & Degrees of Freedom & $F$ value & $P$ value & $R$-square \\
\hline Model & 4 & & & 0.096 \\
Error & 150 & 3.99 & 0.0042 & 0.10 \\
Total & 154 & & & \\
\hline Predictors & Degrees of Freedom & $F$ value & $P$ value & Partial Eta-square \\
\hline Community water & 1 & & & 0.019 \\
Fluoridation & 1 & 2.93 & 0.09 & 0.001 \\
Race & 1 & 0.11 & 0.74 & 0.003 \\
Medication & 1 & 0.38 & 0.54 & 0.080 \\
Sex & & 12.98 & 0.0004 & \\
\hline
\end{tabular}

rates than females (adjusted least square means 1.96 versus $1.53)$.

\section{Discussion}

There were $14.3 \%$ of students entering medical and pharmacy school who had hyposalivation (stimulated salivary flow rate of less than $1 \mathrm{ml} /$ minute). Based upon self-report, there were fewer than 10 students who reported xerostomia. Most of the participants with xerostomia were female and non-Hispanic white. The average salivary flow was greater in males than females in the bivariate analysis. Greater salivary flow was significant for males in a general linear regression model.

However, the association of hyposalivation, as defined by a stimulated salivary flow of $1 \mathrm{ml} /$ minute or less, failed to reach a significant difference between males and females in bivariate analyses or logistic regression analyses. Similarly, hyposalivation failed to reach a significant difference between students using and not using medications in bivariate analyses or logistic regression analyses. It is clinically significant that there were students entering into professional healthcare programs who were unaware of their oral condition in relation to adequacy of saliva and its protective factors.

Professional programs are intensive and it is important to eliminate outdated and peripherally relevant material [3]. There is also a need for learning about critical issues in other professions and developing collaborative networks to benefit patients. The My First Patient experience provides such a pathway by introducing a thread of dentistry into the curriculum of nondental professional programs-a thread that is important in understanding patient cooperation in medication compliance and oral health.

4.1. Similar Studies. The literature has many studies concerning questionnaires about oral dryness and unstimulated saliva; however, there are few studies with which to compare our study of stimulated saliva, sex, and medication use in a young population. In a study of 171 participants, aged 18-33 years, stimulated salivary flow rates were determined to be $1.52 \pm 0.69$ overall, which corresponds with this study's overall stimulated salivary flow rate of $1.53 \pm 0.73$ [26]. However, their results for the overall stimulated salivary flow rates for males and females $(1.54 \pm 0.52$ for males and $1.52 \pm 0.74$ for females $[P=0.84])$ were not significantly different as our results were. In a longitudinal study of children, followed from ages 7 to 12 years, at age 12 years, the average stimulated salivary flow rate was $1.8 \mathrm{ml} /$ minute \pm 0.6 and there was no significant difference between males and females $(P=0.7697)$ [18]. In a study of 55 participants, aged 20-40 years, in which saliva was stimulated with citric acid, there was a significant difference in male and female stimulated salivary rates [27].

Researchers in one study with young adult participants, aged 20 years, found a difference between males and females in the report of oral dryness on a questionnaire in nonmedicated individuals (19.6\% in females and $14.6 \%$ in males) but failed to identify a difference in medicated individuals $(21.9 \%$ in females and $22.1 \%$ in males) [16]. Our study supports those results, although we used stimulated salivary flow rate rather than questionnaire.

4.2. Study Limitations and Strength. The collection of salivary flow rate is very sensitive to many factors including prior eating/drinking, quiet private settings, time of day [28], room humidity, body position, and room temperature among other factors [13]. There is a circadian rhythm for stimulated submandibular gland salivary flow rate, and some of the rhythms for other glandular tissues have a high amplitude (acrophase) which potentially affects study results [28, 29]. Since body temperature also has an acrophase, having participants complete the salivary flow rate test when they had similar body temperatures would have provided internal standards to adjust for the circadian rhythms. Another potential limitation of the study is that some participants may have not reported that they were taking medications or underreported the number of medications that they were taking, possibly because of the stigma associated with taking certain prescription medication categories (e.g., antidepressants). Nevertheless, this study has a large population of young adults as a study strength. There were few missing data points, and the results are important in understanding a complex, challenging condition.

The study underscores the need for curriculum that will help students discover the importance of interprofessionalism and self-knowledge as many of the students were unaware of their hyposalivation and the interventions which were possible. The curriculum for the My First Patient Program helps professional students to be aware of their own salivary flow rate baseline levels and to be aware 
of hyposalivation when discussing medications with their patients. The curriculum includes the collaborative treatment of hyposalivation involving salivary testing and monitoring of medications, as well as pharmacological treatment with salivary stimulants, and prescription fluoride and calcium toothpastes and the suggestion to use sugar-free, nonacidic gum or lozenges and the recommendation of avoiding alcohol containing mouth rinses, smoking, and limited caffeine.

\section{Conclusion}

Hyposalivation is a biomedical, public health concern. It is important for healthcare professionals to have experiences to learn about saliva collection, to provide samples, and to interpret results related to cut points. Such curriculum provides opportunities for collaboration among people of multiple fields and helps each understand the roles and skills of each other.

\section{Disclosure}

The content is solely the responsibility of the authors and does not necessarily represent the official views of the National Institutes of Health.

\section{Conflicts of Interest}

The authors report no conflicts of interest.

\section{Authors' Contributions}

Individual contributions made by each author to the work are as follows: R. Constance Wiener made substantial contributions to the conception and design of the work, data analysis, data interpretation, drafting of the work, revision of the work, and final approval of the version and agrees to be accountable for all aspects of the work. Susan Morgan made substantial contributions to the conception and design of the work, acquisition of the data, drafting of the work, revision of the work, and final approval of the version and agrees to be accountable for all aspects of the work. Lauren Swager made substantial contributions to the conception and design of the work, acquisition of the data, drafting of the work, revision of the work, and final approval of the version and agrees to be accountable for all aspects of the work. Christina DeBiase made substantial contributions to the conception and design of the work, acquisition of the data, revision of the work, and final approval of the version and agrees to be accountable for all aspects of the work. Christa Lilly made substantial contributions to the conception and design of the work, data analysis, data interpretation, revision of the work, and final approval of the version and agrees to be accountable for all aspects of the work.

\section{Acknowledgments}

Research reported in this publication was supported by the National Institute of General Medical Sciences of the National Institutes of Health under Award no. U54GM104942, the
Claude Worthington Benedum Foundation, and Office of Inter-Professional Education at West Virginia University Health Sciences Center. The authors would like to acknowledge those individuals that originally implemented and have continued to organize the My First Patient Program at West Virginia University. Through their efforts to implement and sustain this interprofessional program designed to make future healthcare providers cognizant of their own health goals, this program evolved. Those involved with the program include Pat Chase; Travis White; Louise Veselicky; Ann Cather; Matt Gurk; David Wilkes; Patrick Maarshlek; and Ryan Sommerkorn.

\section{References}

[1] A. B. Douglass, W. Gonsalves, R. Maier et al., "Smiles for life: a national oral health curriculum for family medicine. A model for curriculum development by STFM groups," Family Medicine, vol. 39, no. 2, pp. 88-90, 2007.

[2] C. Hein, D. J. Schönwetter, and A. M. Iacopino, "Inclusion of oral-systemic health in predoctoral/undergraduate curricula of pharmacy, nursing, and medical schools around the world: A preliminary study, Journal of Dental Education, vol. 75, no. 9, pp. 1187-1199, 2011.

[3] W. D. Hendricson and P. A. Cohen, "Oral health care in the 21st century: Implications for dental and medical education," Academic Medicine, vol. 76, no. 12, pp. 1181-1206, 2001.

[4] W. E. Mouradian, A. Reeves, S. Kim et al., "An oral health curriculum for medical students at the university of Washington," Academic Medicine, vol. 80, no. 5, pp. 434-442, 2005.

[5] J. Freeman and A. Dobbie, "Innovations in Family Medicine Education," Family Medicine, vol. 39, no. 2, pp. 88-90, 2007.

[6] K. M. Stack and A. S. Papas, "Xerostomia: etiology and clinical management," Nutrition in Clinical Care, vol. 4, no. 1, pp. 15-21, 2001.

[7] J. M. Plemons, I. Al-Hashimi, and C. L. Marek, "Managing xerostomia and salivary gland hypofunction: Executive summary of a report from the American Dental Association Council on Scientific Affairs," Journal of the American Dental Association, vol. 145, no. 8, pp. 867-873, 2014.

[8] C. Smith, "Kidney Disease and 'Bad Teeth"' Clinician Reviews, vol. 26, no. 1, pp. 20-22, 2016.

[9] L. M. Streebny and A. Vissink, Dry Mouth: The Malevolent Symptom: A Clinical Guide, Wiley-Blackwell, Ames, IA, USA, 2010.

[10] R. C. Wiener, B. Wu, R. Crout et al., "Hyposalivation and xerostomia in dentate older adults," The Journal of the American Dental Association, vol. 141, no. 3, pp. 279-284, 2010.

[11] A. Bardow, F. Lagerlof, B. Nauntofte et al., "The role of saliva," in Dental Caries: The Disease and Its Clinical Management, O. Fejerskov and E. Kidd, Eds., vol. 195, Blackwell Munksgaard, Oxford, United Kingdom, 2008.

[12] N. D. Joanna and W. M. Thomson, "Dry mouth - an overview," Singapore Dental Journal, vol. 36, pp. 12-17, 2015.

[13] L. W. Swager and S. K. Morgan, "Psychotropic-induced dry mouth: don't overlook this potentially serious side effect: routine screening, education can help patients avoid substantial sequelae," Current Psychiatry, vol. 10, no. 12, p. 54, 2011.

[14] J. Guggenheimer and P. A. Moore, "Xerostomia," The Journal of the American Dental Association, vol. 134, no. 1, pp. 61-69, 2003. 
[15] C. Dawes, "Physiological factors affecting salivary flow rate, oral sugar clearance, and the sensation of dry mouth in man.," Journal of Dental Research, vol. 66, pp. 648-653, 1987.

[16] T. Nederfors, "Xerostomia and hyposalivation," Advances in Dental Research, vol. 14, pp. 48-56, 2000.

[17] J. D. B. Featherstone, S. Domejean-Orliaguet, L. Jenson, M. Wolff, and D. A. Young, "Caries risk assessment in practice for age 6 through adult," Journal of the California Dental Association, vol. 35, no. 10, pp. 703-713, 2007.

[18] L. Sánchez-Pérez, E. Irigoyen-Camacho, L. Sáenz-Martínez, M. Zepeda Zepeda, E. Acosta-Gío, and I. Méndez-Ramírez, "Stability of unstimulated and stimulated whole saliva flow rates in children," International Journal of Paediatric Dentistry, vol. 26, no. 5, pp. 346-350, 2016.

[19] S. Mizutani, D. Ekuni, T. Tomofuji et al., "Relationship between xerostomia and gingival condition in young adults," Journal of Periodontal Research, vol. 50, no. 1, pp. 74-79, 2015.

[20] W. M. Thomson, H. P. Lawrence, J. M. Broadbent, and R. Poulton, "The impact of xerostomia on oral-health-related quality of life among younger adults," Health and Quality of Life Outcomes, vol. 4, article 86, 2006.

[21] T. Nederfors, R. Isaksson, H. Mörnstad, and C. Dahlöf, "Prevalence of perceived symptoms of dry mouth in an adult Swedish population-relation to age, sex and pharmacotherapy," Community Dentistry and Oral Epidemiology, vol. 25, no. 3, pp. 211216, 1997.

[22] S. K. Veerabhadrappa, P. R. Chandrappa, S. Patil, S. Y. Roodmal, A. Kumarswamy, and M. K. Chappi, "Evaluation of xerostomia in different psychological disorders: an observational study," Journal of Clinical and Diagnostic Research, vol. 10, no. 9, article 42, 2016.

[23] Z. Wang, M.-M. Shen, X.-J. Liu, Y. Si, and G.-Y. Yu, "Characteristics of the saliva flow rates of minor salivary glands in healthy people," Archives of Oral Biology, vol. 60, no. 3, pp. 385-392, 2015.

[24] A. Prodan, H. S. Brand, A. J. M. Ligtenberg et al., "Interindividual variation, correlations, and sex-related differences in the salivary biochemistry of young healthy adults," European Journal of Oral Sciences, vol. 123, no. 3, pp. 149-157, 2015.

[25] H. Inoue, K. Ono, W. Masuda et al., "Gender difference in unstimulated whole saliva flow rate and salivary gland sizes," Archives of Oral Biology, vol. 51, no. 12, pp. 1055-1060, 2006.

[26] P. M. Carvalho, P. M. Castelo, G. H. Carpenter, and M. B. D. Gavião, "Masticatory function, taste, and salivary flow in young healthy adults," Journal of Oral Science, vol. 58, no. 3, pp. 391399, 2016.

[27] W. Li-Hui, L. Chuan-Quan, Y. Long, L. Ru-Liu, C. Long-Hui, and C. Wei-Wen, "Gender differences in the saliva of young healthy subjects before and after citric acid stimulation," Clinica Chimica Acta, vol. 460, pp. 142-145, 2016.

[28] C. Dawes, "Circadian rhythms in human salivary flow rate and composition," The Journal of Physiology, vol. 220, no. 3, pp. 529545, 1972.

[29] F. Halberg, J. Reinhardt, F. C. Bartter et al., "Agreement in endpoints from circadian rhythmometry on healthy human beings living on different continents," Experientia, vol. 25, no. 1, pp. 107-112, 1969. 


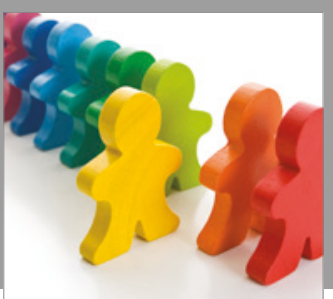

Autism

Research and Treatment
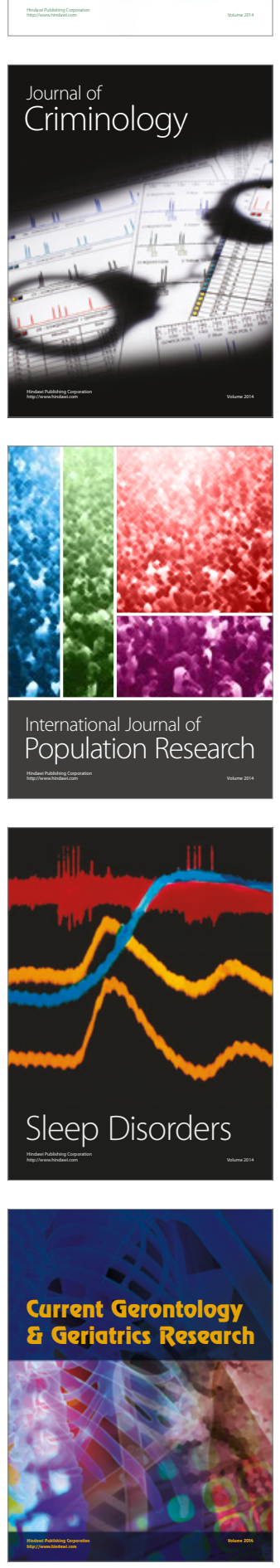

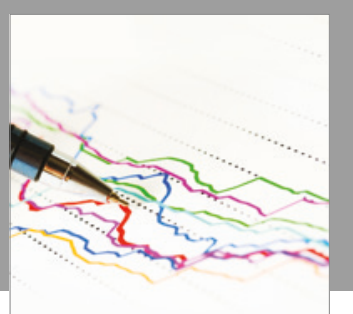

Economics

Research International

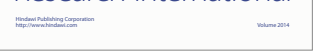

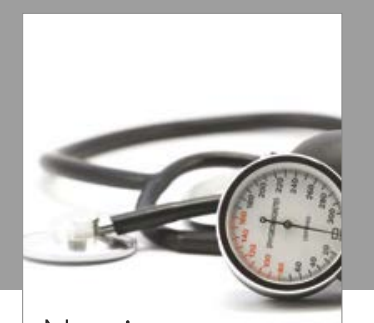

Nursing

Research and Practice

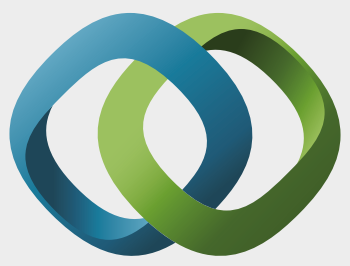

\section{Hindawi}

Submit your manuscripts at

https://www.hindawi.com
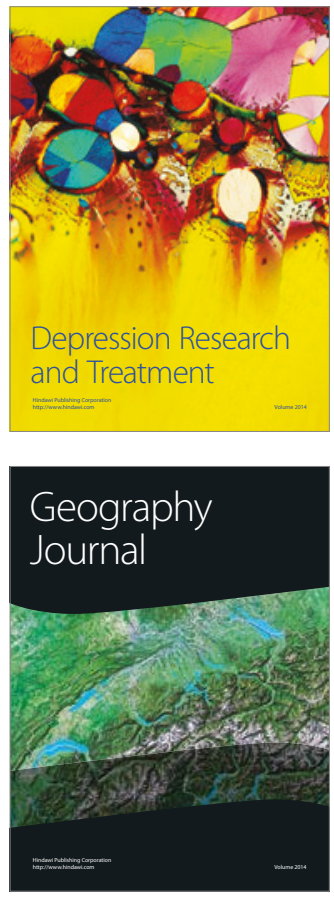
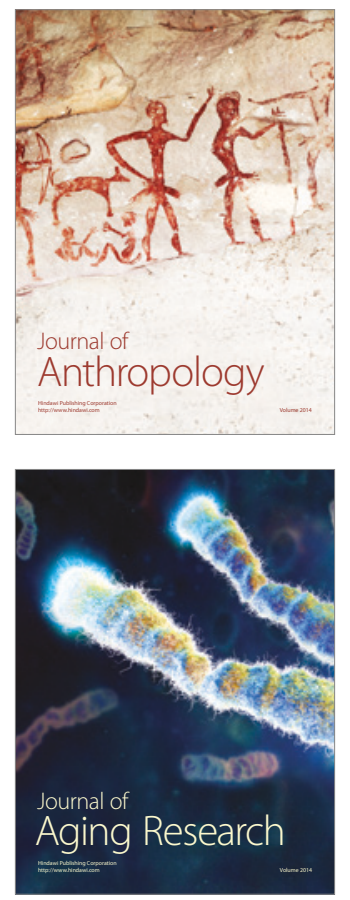
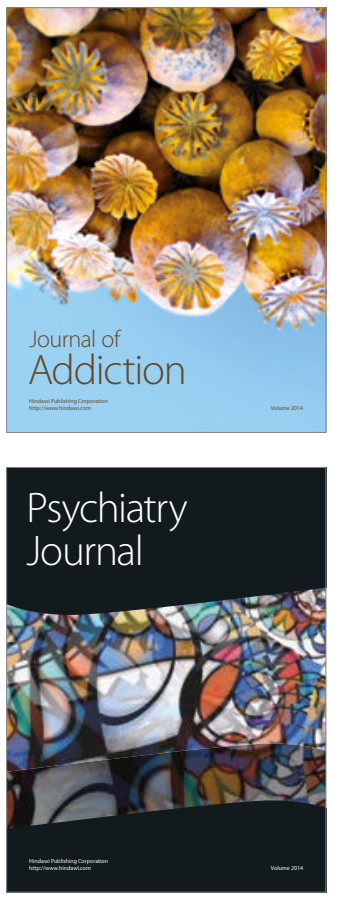

Child Development

Research

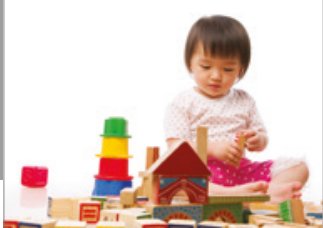

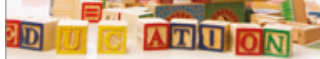
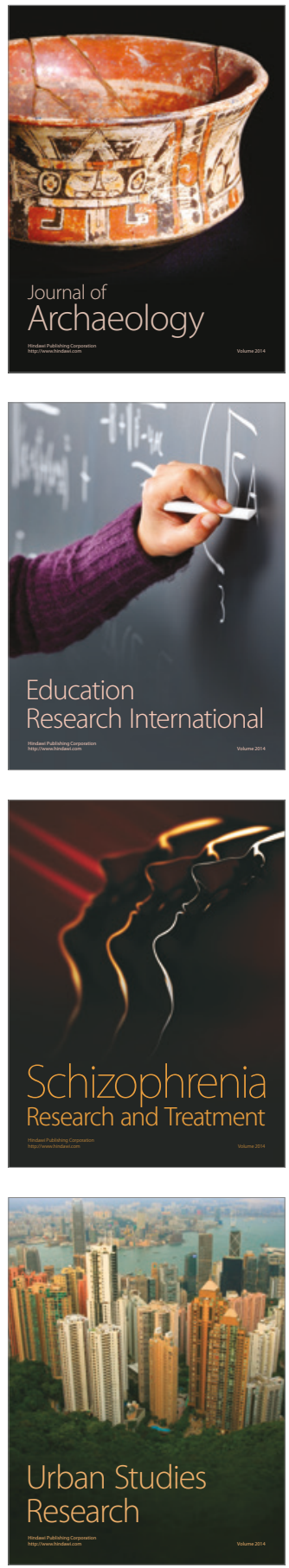